\title{
Increased reproductive success in older female red kangaroos and the impact of harvesting
}

\author{
A. R. Pople', S. C. Cairns ${ }^{2}$ and S. R. McLeod ${ }^{3}$ \\ ' Biosecurity Queensland, Department of Employment, Economic Development and Innovation, \\ PO Box 36, Sherwood Queensland 4075. tony.pople@dpi.qld.gov.au \\ ${ }^{2}$ School of Environmental and Rural Sciences, University of New England,Armidale NSW 235 I. \\ scairns@une.edu.au \\ ${ }^{3}$ Vertebrate Pest Research Unit, Department of Primary Industries, Forest Road, Orange NSW 2800 \\ steven.mcleod@dpi.qld.gov.au
}

Wildlife harvesting has a long history in Australia, including obvious examples of overexploitation.
Not surprisingly, there is scepticism that commercial harvesting can be undertaken sustainably.
Kangaroo harvesting has been challenged regularly at Administrative Appeals Tribunals and elsewhere
over the past three decades. Initially, the concern from conservation groups was sustainability of the
harvest. This has been addressed through regular, direct monitoring that now spans $>30$ years and
a conservative harvest regime with a low risk of overharvest in the face of uncertainty. Opposition
to the harvest now continues from animal rights groups whose concerns have shifted from overall
harvest sustainability to side effects such as animal welfare, and changes to community structure,
genetic composition and population age structure. Many of these concerns are speculative and
difficult to address, requiring expensive data.

One concern is that older females are the more successful breeders and teach their daughters optimal habitat and diet selection. The lack of older animals in a harvested population may reduce the fitness of the remaining individuals; implying population viability would also be compromised. This argument can be countered by the persistence of populations under harvesting without any obvious impairment to reproduction. Nevertheless, an interesting question is how age influences reproductive output. In this study, data collected from a number of red kangaroo populations across eastern Australia indicate that the breeding success of older females is up to $7-20 \%$ higher than that of younger females. This effect is smaller than that of body condition and the environment, which can increase breeding success by up to $30 \%$ and $60 \%$ respectively. Average age of mature females in a population may be reduced from 9 to 6 years old, resulting in a potential reduction in breeding success of 3-4\%. This appears to be offset in harvested populations by improved condition of females from a reduction in kangaroo density.

There is an important recommendation for management. The best insurance policy against overharvest and unwanted side effects is not research, which could be never-ending. Rather, it is a harvest strategy that includes safeguards against uncertainty such as harvest reserves, conservative quotas and regular monitoring. Research is still important in fine tuning that strategy and is most usefully incorporated as adaptive management where it can address the key questions on how populations respond to harvesting.

Key words: harvest management, Macropus rufus, sustainable use, demography

\section{Introduction}

Despite well-developed ecological theory to support sustained-yield harvesting, it has proven difficult to exploit wildlife populations sustainably. Economic and social factors often conspire to take yields that cannot be maintained leading to many examples of overexploitation (Ludwig et al. 1993; Ludwig 2001). In Australia, examples include overharvest of whale and seal populations, particularly in the early days of settlement (Hughes 1987). This has resulted in the sustainability of any harvesting operation being questioned and, in some cases, actively opposed. Nevertheless, where the principles of sustained-yield harvesting can be applied, and this has been the deficiency (Ludwig 2001), wildlife harvesting has been sustainable (e.g. Gunn 2001; Hutton and Dickson 2001; Marine Stewardship Council 2002; Forest Stewardship Council 2003; McShea et al. 1997; Webb 2002; Williams et al. 2002).
Kangaroo harvesting has been challenged repeatedly over the past 30 years, at Administrative Appeals Tribunals and other forums (see Pople and Grigg 1998 for a discussion). The initial concern was conservation, but this has largely been addressed through regular, direct monitoring of harvested kangaroo populations for over 30 years. This monitoring has revealed abundant, widespread populations of each species that have fluctuated largely in concert with environmental conditions and allowed the harvest to be identified as a small percentage of absolute population size. Most importantly, conservative quotas have been set as a percentage of these population estimates, which is recognised as a safe harvesting strategy (Caughley 1987; Engen et al. 1997; Pople 2008). McCallum (1999) regarded this as a necessary demonstration of sustainability, as the monitoring system ensured that the harvest was not only 
sustainable, but was seen as such. Regular estimates of population size using tangible counting methods such as aerial survey provide a far more convincing case for sustainability than complex population models based on harvest data. In many wildlife-harvesting operations, particularly fisheries, harvest data (e.g. catch-per-uniteffort) are used to indirectly monitor the population. Overexploitation of fish populations has often resulted from an inability to detect declining stocks in the catch data (Hilborn and Walters 1992). In stark contrast, kangaroo management uses data, primarily from aerial survey, that are independent of the harvest and free of the usually untested assumptions associated with indirect monitoring.

Opposition to kangaroo harvesting now comes from animal rights groups with concerns over side effects (see Wilson 1999). The potential side effects of harvesting are well recognised (e.g. Caughley 1983; Pople and Grigg 1998), and include reductions in average population size, increases in the resource base, and changes in age structure, gene frequencies and a population's dynamic behaviour, and changes to community structure. For kangaroos, the likely effects appear to be of little conservation concern (Pople and Grigg 1998). Animal welfare has also been a concern, as some kangaroos are only wounded when shot and some young-at-foot are orphaned.

One concern is that harvesting will have a detrimental effect on the reproductive output of a population, compromising sustainability. Non-selective harvesting will reduce the average age of individuals in a population. This effect is exacerbated in kangaroos because harvesters preferentially shoot larger, older animals as larger skins and heavier carcasses are more valuable (Pople 1996). Kangaroos continue to grow through life, although females to a lesser extent than males, and so older animals of a particular sex tend to be larger (Jarman 1989; Pople 1996). Croft (2004) argued that older females are important to the overall reproductive success of a kangaroo population. Older red kangaroo females appear to have a higher probability of rearing young through to weaning (Bilton and Croft 2004). In addition, their daughters can learn habitat and diet selection from their mothers by being allowed to remain in the natal home range. Thus, if maternal age has a strong influence on breeding success, then a reduction in the average age of females in a population through harvesting could alter a population's dynamics more than expected from simply reducing the proportion of mature animals. Thus, it should be useful to see the extent to which reproductive success increases with maternal age. This was one aim of this study. A second aim was to consider whether such an assessment was important to ensure the sustainability of kangaroo harvesting.

\section{Methods}

This project used data on female age, body condition, and the age and presence of young from 922 mature, red kangaroo females randomly shot from seven widely separated locations in eastern Australia (Fig. 1) ( $n$ at each

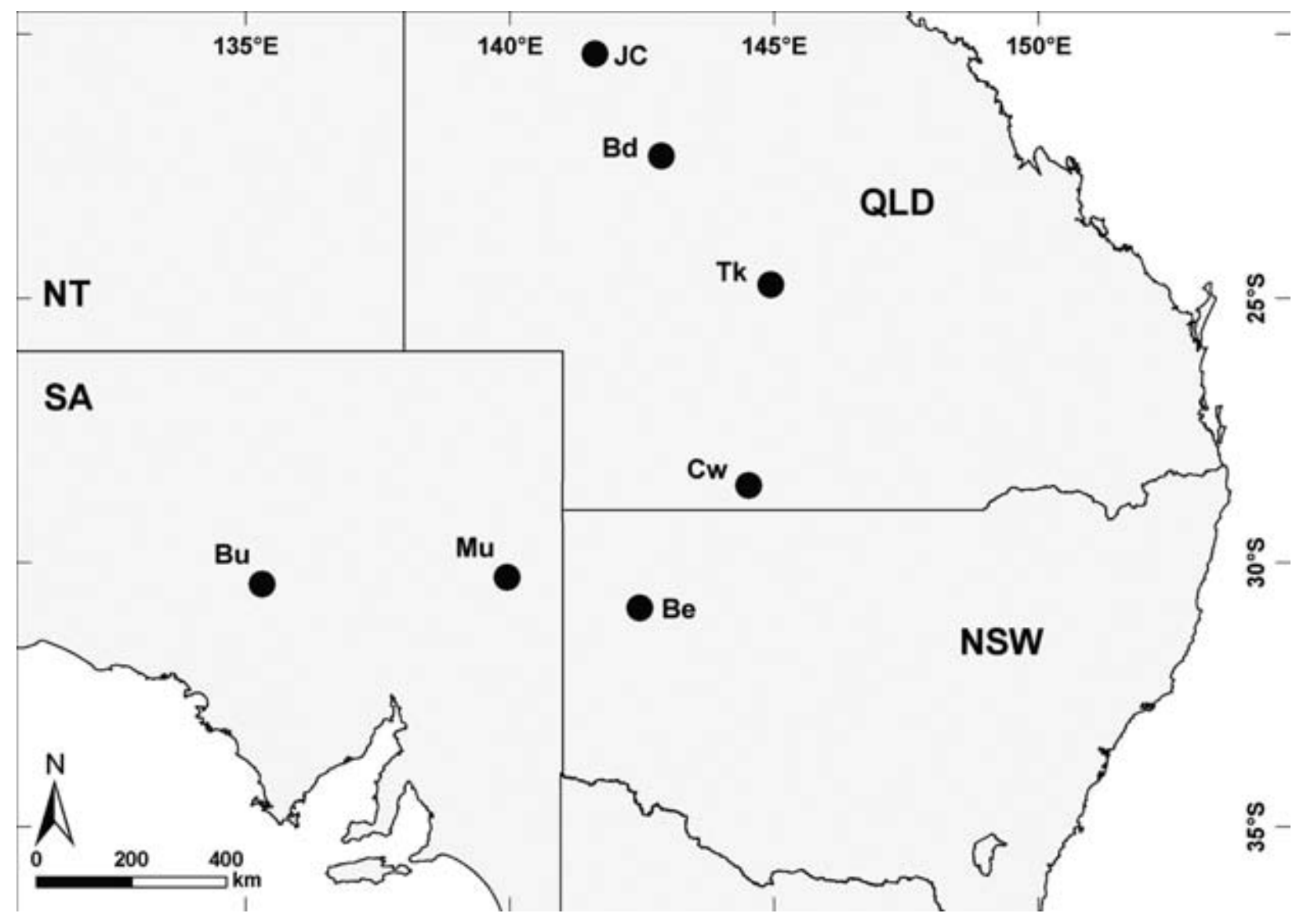

Figure I. Location of study sites where random shot samples of red kangaroos were taken. Sampling years are shown in brackets. JC, Julia Creek (1995, 1996); Bd, Bladensburg (1995); Te, Terrick Terrick (1993); Cw, Currawinya (1993); Be, Boorungie (2000); Mu, Mulyungarie (1993); Bu, Bulgunnia (1993). 
location ranged 79-228) in most cases in a single year at each location between 1993 and 2000, thus spanning a broad range of environmental conditions. Harvest rate also varied considerably across the seven locations. These animals form a subset of population samples taken in a number of studies to assess aspects of the demography of red kangaroos (Pople and Cairns 1995; Pople 1996; Hacker et al. 2003; Pople 2006). Details of methods are given in the references. Briefly, maternal age was determined for South Australian and Queensland sites from a molar index (Kirkpatrick 1970, with a 95\% confidence interval of \pm 0.3 years). At Boorungie in New South Wales, eye lens weight was used to estimate age, which McLeod et al. (2006) considered was suitable for grouping animals into 1-2 age classes. At all sites, a pouch young's age was determined from its hind foot length (Kirkpatrick 1970, with a 95\% confidence interval of $\pm 2-7 \%$ of estimated age). The presence of a young-at-foot was determined by the presence of a lactating teat (other than that suckling the pouch young) (Frith and Sharman 1964). Only sexually mature females were used in the analysis, with maturity determined from maternal age, the condition of the pouch and teats and in some cases the reproductive tract (Sharman 1964).

Breeding success in female red kangaroos has been measured elsewhere by the proportion of females with young-at-foot and by mean pouch young age (e.g. Newsome 1965; Shepherd 1987). These measures may be confounded by the fact that females with pouch young $>120$ days old will have weaned their young-at-foot. Pouch young age and the proportion of females with young-at-foot therefore need to be considered together. One way of achieving this is to determine whether females are breeding to full potential (bfp). Females with pouch

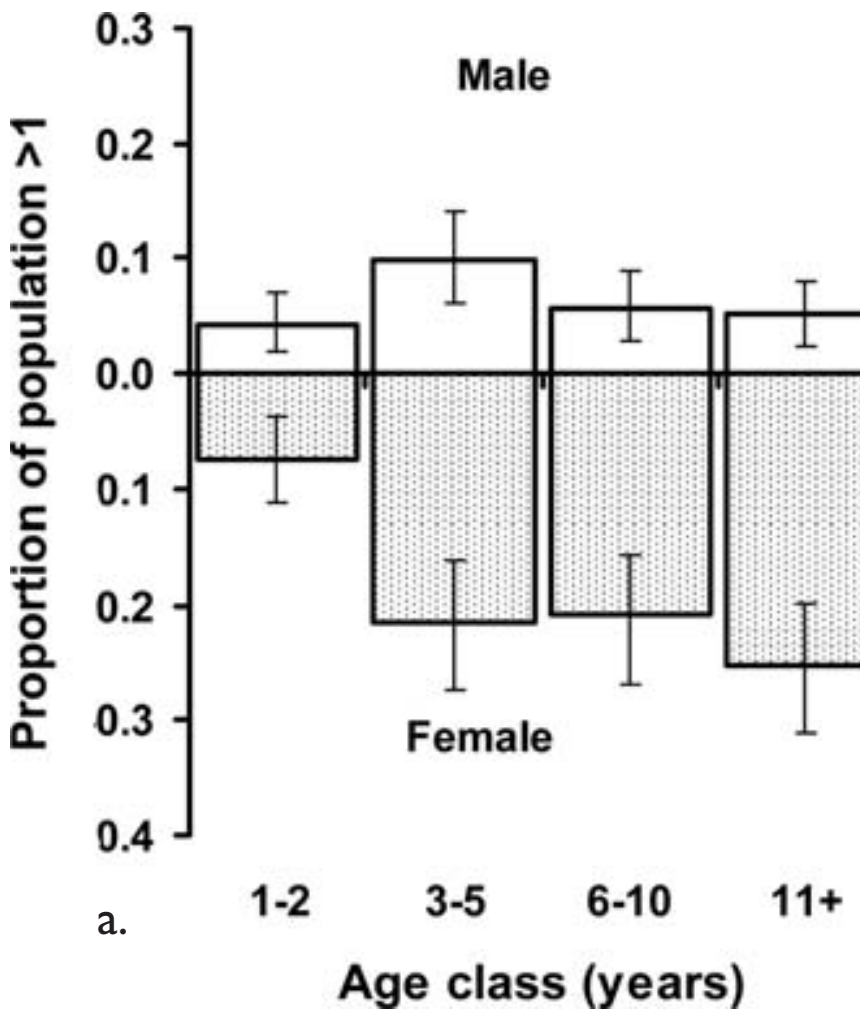

young $<120$ days old and no young-at-foot are not breeding to full potential. Females with pouch young $>$ 120 days old, or with pouch young and a young-at-foot, are breeding to full potential. The percentage of females breeding to full potential (\%bfp) in a sample can then be used as a measure of breeding success. Only females $\geq 3$ years old were considered in the statistic because younger females may have been rearing their first young.

Logistic regression was used to model the influence of maternal body condition, age and 'location' (i.e. the study site) as a proxy for local environmental conditions, on \%bfp. An index of maternal body condition was calculated from the residuals of the multiple regression of $\log ($ body weight) as a function of $\log$ (age), log(hind foot length) and again the dummy variable 'location'. This relationship accounted for the non-linear relationship between body weight and a one-dimensional quantity such as length and the known variation in growth patterns between geographically-separated study sites (Pople 2006).

Analyses were performed using R 1.9.1 (R Development Core Team 2003). Models were simplified by stepwise removal of non-significant $(\mathrm{P}>0.05)$ terms from the full model (Crawley 2002).

\section{Results}

Harvesting can clearly and not surprisingly alter the age structure of both sexes in kangaroo populations (Pople 1996, 2006). An example of this effect is shown in Figure 2, where there is a greater proportion of older individuals of both sexes in the unharvested population at Currawinya, compared with the heavily-harvested population at Terrick Terrick.
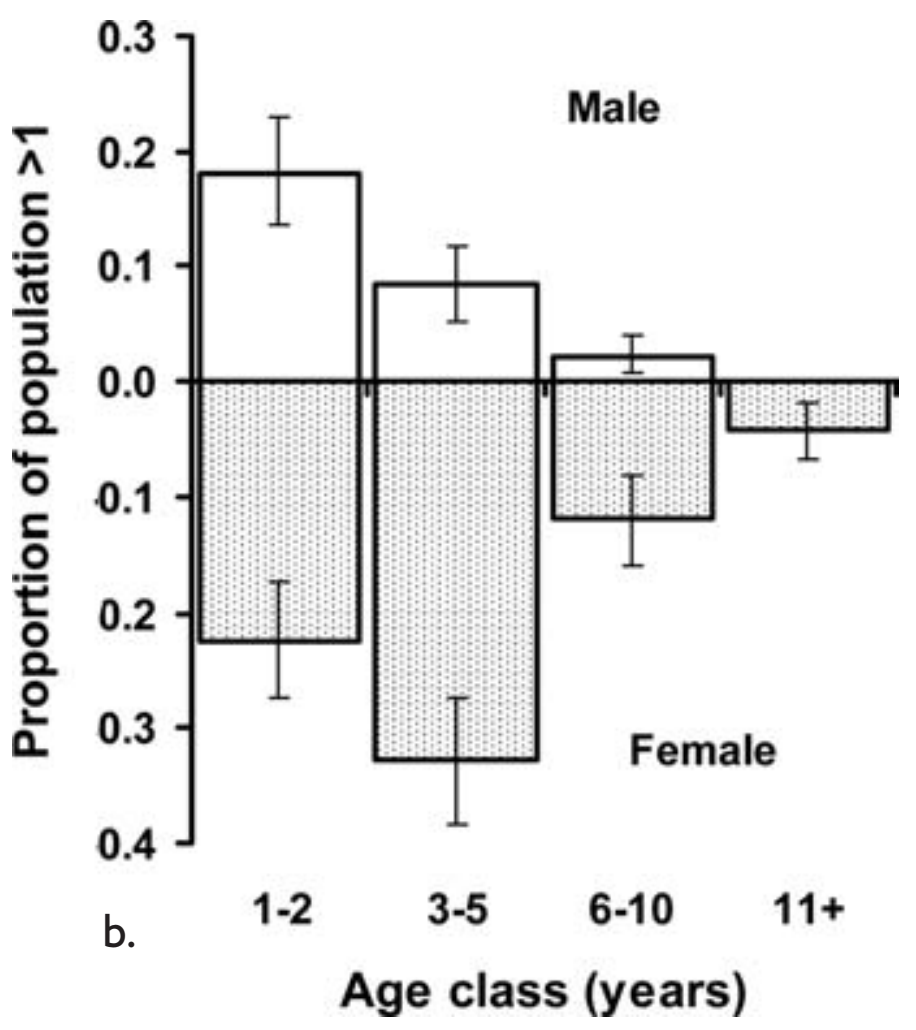

Figure 2. Age structures of (a) an unharvested red kangaroo population at Currawinya and (b) a harvested red kangaroo population at Terrick Terrick in eastern Australia (Fig. I) sampled over 1993-95. Bars (stippled, female; open, male) represent the proportions ( $\pm 95 \% \mathrm{Cl}$ from bootstrapping) of the non-juvenile population in each age class. 
$\log$ (body weight) was best modelled as a function of the main effects $\log ($ age), $\log$ (hind foot length) and location. There was no support for the inclusion of interactions between these variables.

The most parsimonious model predicting \%bfp included all three terms, maternal age, body condition and location, but no interactions. There was no strong evidence of overdispersion. The final model took the form:

$\%$ bfp $=100 \times 1 /(1+1 / \exp ($ intercept + age + condition + location))

Parameter estimates are shown in Table 1 . The relative influences of each term in the model can be seen graphically by comparing how much each variable affects \%bfp (Fig. 3). Depending on the value of age and condition, location is responsible for variation in $\%$ bfp of up to $60 \%$. Holding condition constant, maternal age changes \%bfp by $7-20 \%$ (Fig. 3a). Finally, holding age constant, condition changes \%bfp by up to $30 \%$ (Fig. 3 b). Environmental conditions are clearly the major determinant of reproductive success, although within a site there will be variation in body condition among individuals. Maternal age is a lesser influence.

The potential effect of harvesting on reproductive success can be quantified by comparing the average age of mature females in the two populations shown in Figure 2, which represent the extremes in average age among the seven populations sampled. At Currawinya, which is unharvested, the average age of mature females is 9 years old. At Terrick Terrick, which is heavily harvested, the average age of mature females is 6 years old. Using the logistic regression model described above, this reduction in average age would result in a reduction in breeding success of $3-4 \%$, where condition ranges $-0.2-0.2$. The result is virtually identical if the actual age distributions are used rather than average age to calculate breeding success.

Table I. Parameter estimates and associated standard errors for the minimal adequate logistic regression model describing the proportion of red kangaroo females breeding to full potential as a function of maternal age, maternal body condition and location (i.e. dummy variables for seven study sites). See text for details.

\begin{tabular}{lcc}
\hline Parameter & Estimate & Standard error \\
\hline age & 0.053 & 0.020 \\
\hline condition & 3.263 & 0.844 \\
\hline intercept (Bladensberg) & -1.027 & 0.277 \\
\hline location (Julia Creek) & 0.584 & 0.315 \\
\hline location (Terrick Terrick) & 0.848 & 0.304 \\
\hline location (Currawinya) & 0.871 & 0.308 \\
\hline location (Bulgunnia) & 1.325 & 0.321 \\
\hline location (Boorungie) & 1.740 & 0.306 \\
\hline location (Mulyungarie) & 2.729 & 0.369 \\
\hline
\end{tabular}
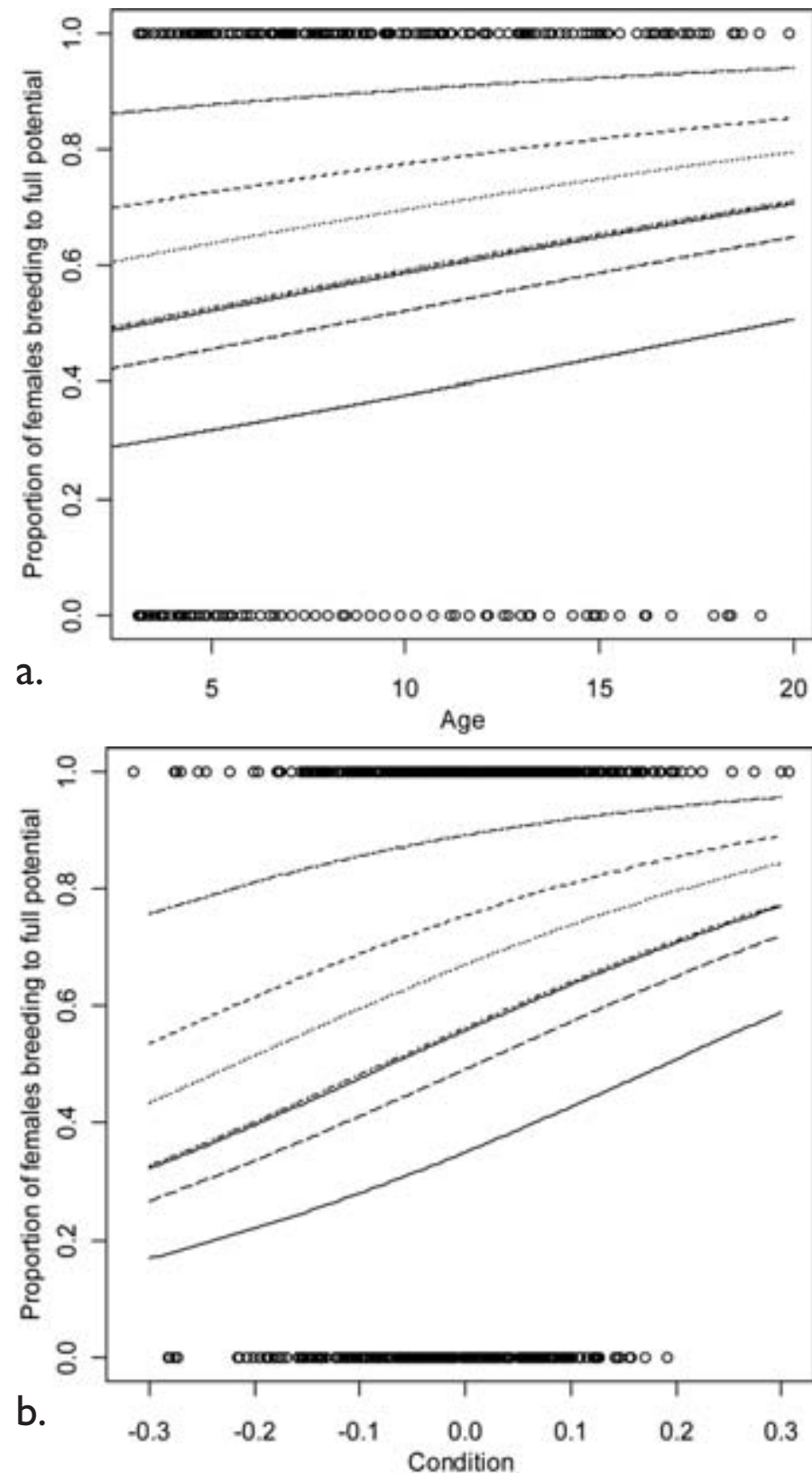

Figure 3. Fitted logistic regression model predicting reproductive success (i.e. proportion breeding to full potential, bfp) in red kangaroos. Lines represent separate sites across eastern Australia (Fig. I). From top to bottom in each Figure, the sites are Mulyungarie, Boorungie, Bulgunnia, Currawinya, Terrick Terrick, Julia Creek and Bladensburg. The horizontal line of circles at the top and bottom of each Figure (i.e. 0 and I proportion bfp) represent the binary data, showing the distribution of sampled kangaroos across age and condition. The influence of maternal age on proportion bfp is shown in (a) and the influence of body condition is shown in (b).

\section{Discussion}

These results could be incorporated into population models to examine the extent to which changes in age structure reduce rates of recruitment. The indications here are that it would be slight, as Bilton and Croft (2004) similarly suggested for the influence of maternal age on a female red kangaroo's 
lifetime reproductive success. Nevertheless, studies of the population dynamics of harvested populations suggest these populations are not experiencing longterm decline through depressed recruitment following the removal of older, more reproductively-successful animals that are 'educators' of new recruits. A likely explanation for the lack of any decline is that female reproductive success and juvenile survival is enhanced in harvested populations with a reduction in density and subsequent greater availability of resources. Comparisons of breeding success and juvenile survival in harvested and unharvested populations have provided supporting data for this explanation (Pople 1996).

It is tempting to recommend further research such as modelling to explore the effects of reduced reproductive output from a reduction in average age of mature female kangaroos. It is also easy to speculate on other potential impacts of harvesting, with the onus on management to prove no detrimental effect. This can spawn a continuous cycle of questioning and response through often expensive research. However, improved understanding of kangaroo biology is not necessarily going to avoid overharvesting and unwanted side-effects. Such safeguards, with the exceptions of those for animal welfare concerns, are achieved through the harvest strategy which, as outlined earlier, involves conservative quotas that are set as proportions of regular estimates of population size. Harvest reserves such as National Parks provide a further safety net (Gell and Roberts 2003; Tenhumberg et al. 2004).

Certainly, some basic ecology of the harvested species is required in developing a harvest strategy. However, the research that is usually required is on how populations respond to harvesting. The complexities of ecological systems dictate that this is best done as experimental or adaptive management (Walters 1986), rather than independent of the harvest and thus requiring extrapolation. With an appropriate, conservative harvest strategy and sufficient monitoring, such an approach can still be precautionary (Parma et al. 1998).

\section{Acknowledgements}

Norbert Menke is thanked for providing the map. Gordon Maag is also thanked for collecting many of the shot samples in Queensland, as is Russell Palmer for collecting many of the shot samples in South Australia. A number of commercial harvesters were also involved in sample collection and their efforts are similarly appreciated.

\section{References}

Bilton, A.D. Croft, D.B. 2004. Lifetime reproductive success in a population of female red kangaroos Macropus rufus in the sheep rangelands of western New South Wales: environmental effects and population dynamics. Australian Mammalogy 26: 45-60.

Caughley, G. 1983. Dynamics of large mammals and their relevance to culling. Pp. 115-126 in Management of Large Mammals in African Conservation Areas, edited by R.N. OwenSmith. Haum, Pretoria.

Caughley, G. 1987. Ecological relationships. Pp. 159-187 in Kangaroos: their Ecology and Management in the Sheep Rangelands of Australia, edited by G. Caughley, N. Shepherd and J. Short. Cambridge University Press: Cambridge.

Crawley, M.J. 2002. Statistical computing: an introduction to data analysis using S-Plus. Wiley, Chichester, West Sussex.

Croft, D.B. 2004. Kangaroo management: individuals and communities. Australian Mammalogy 26: 101-108.

Engen, S., Lande, R., and Saether, B.-E. 1997. Harvesting strategies for fluctuating populations based on uncertain population estimates. Journal of Theoretical Biology 186: 201-212.

Frith, H.J. and Sharman, G. 1964. Breeding in wild populations of the red kangaroo, Megaleia rufa. CSIRO Wildlife Research 9: 86-114.

Forest Stewardship Council 2003. www.fsc.org. Accessed February 2008.

Gell, F.R. and Roberts, C.M. 2003. Benefits beyond boundaries: The fishery effects of marine reserves. Trends in Ecology and Evolution 18: 448-455.

Gunn, A. 2001. Conservation and resource use in Arctic ecosystems. Pp. 424-439 in Conservation of Exploited Species, edited by J. Reynolds, G. Mace, K. Redford and J. Robinson. Cambridge University Press, Cambridge.
Hacker, R.B., McLeod, S.R. and Druhan, J. 2003. Final Report for Project \#D8003. Evaluating Alternative Management Strategies for Kangaroos in the Murray Darling Basin. NSW Department of Agriculture, Dubbo.

Hilborn, R. and Walters, C.J. 1992. Quantitative Fisheries Stock Assessment: Choice, Dynamics and Uncertainty. Chapman and Hall, New York.

Hughes, R. 1987. The Fatal Shore. The Harvill Press, London.

Hutton, J. and Dickson, B. 2001. Conservation out of exploitation: a silk purse from a sow's ear? Pp. 440-461 in Conservation of Exploited Species, edited by J. Reynolds, G. Mace, K. Redford and J. Robinson. Cambridge University Press, Cambridge.

Jarman, P.J. 1989. Sexual dimorphism in Macropodoidea. Pp. 433-447 in Kangaroos, Wallabies and Rat-kangaroos, edited by G. Grigg, P. Jarman and I. Hume. Surrey Beatty and Sons, Sydney.

Kirkpatrick, T.H. 1970. Studies of Macropodidae in Queensland. 8. Age estimation in the red kangaroo (Megaleia rufa (Desmarest)). Queensland Journal of Agricultural and Animal Science 27: 461-462.

Ludwig, D. 2001. Can we exploit sustainably? Pp. 16-38 in Conservation of Exploited Species edited by J. Reynolds, G. Mace, K. Redford, and J. Robinson. Cambridge University Press, Cambridge.

Ludwig, D., Hilborn, R. and Walters, C. 1993. Uncertainty, resource exploitation, and conservation: lessons from history. Science 260: 17-36.

Marine Stewardship Council 2002. www.msc.org. Accessed February 2008.

McCallum, H.I. 1999. How to count kangaroos. Australian Zoologist 31: 309-316. 
McLeod, S.R., Druhan, J. P. and Hacker, R. B. 2006. Estimating the age of kangaroos using eye lens weight. Wildlife Research 33: 25-28.

McShea, W.J., Underwood, H.B. and Rappole, J.H. 1997. The Science of Overabundance: Deer Ecology and Population Management. Smithsonian Institution, Washington.

Newsome, A.E. 1965. Reproduction in natural populations of the red kangaroo, Megaleia rufa (Desmarest), in central Australia. Australian Journal of Zoology 13: 735-759.

Parma, A.M., Amarasekare, P., Mangel, M., Moore, J., Murdoch, W.W., Noonburg, E., Pascual, M.A., Possingham, H.P., Shea, K., Wilcox, C. and Yu, D. 1998. What can adaptive management do for our fish, food, and biodiversity? Integrative Biology 1: 16-26.

Pople, A.R. 1996. Effects of harvesting upon the demography of red kangaroos in western Queensland. $\mathrm{PhD}$ thesis, The University of Queensland, Brisbane.

Pople, A.R. 2006. Modelling the spatial and temporal dynamics of kangaroo populations for harvest management. Final report to the Department of Environment and Heritage, Canberra.

Pople, A.R. 2008. Frequency and precision of aerial surveys for kangaroo management. Wildlife Research 35: 340-348.

Pople, A. and Cairns, S. 1995. Impact of harvesting on kangaroos. Pp. 224-229 in Conservation through Sustainable Use of Wildlife, edited by G. Grigg, P. Hale and D. Lunney. Centre for Conservation Biology, The University of Queensland, Brisbane.
Pople, A.R. and Grigg, G.C. 1998. Commercial harvesting of kangaroos in Australia. Environment Australia, Canberra. http:// www.ea.gov.au/biodiversity/trade-use/wild-harvest/kangaroo/ harvesting/index.html

R Development Core Team 2003. R: A language and environment for statistical computing. R Foundation for Statistical Computing: Vienna, Austria. http://www.R-project.org

Sharman, G.B. 1964. The female reproductive system of the red kangaroo, Megaleia rufa. CSIRO Wildlife Research 9: 50-57.

Shepherd, N. 1987. Condition and recruitment of kangaroos. Pp. 135-158 in Kangaroos: their Ecology and Management in the Sheep Rangelands of Australia, edited by G. Caughley, N. Shepherd and J. Short. Cambridge University Press, Cambridge.

Tenhumberg, B., Tyre, D., Pople, A. and Possingham, H. 2004. Do harvest refuges buffer kangaroos against evolutionary responses to selective harvesting? Ecology 85: 2003-20017.

Walters, C.J. 1986. Adaptive management of renewable resources. McGraw-Hill, New York.

Webb, G.J.W. 2002. Conservation and sustainable use of wildlife: An evolving concept. Pacific Conservation Biology 8: $12-26$.

Williams, B.K., Conroy, M.J. and Nichols, J.D. 2002. Analysis and Management of Animal Populations : Modeling, Estimation, and Decision Making. Academic Press, San Diego, CA.

Wilson, M. (ed.) 1999. The Kangaroo Betrayed. Hill of Content Publishing, Melbourne. 